\title{
Impacts of feed-in tariff policies on design and performance of CCHP
}

\author{
system in different climate zones
}

\author{
C.Y.Zheng J.Y.Wu* X.Q. Zhai R.Z Wang \\ Institute of Refrigeration and Cryogenics, Shanghai Jiao Tong University, Shanghai, \\ 200240, China
}

\begin{abstract}
In this paper, a feed-in tariff policy which can contribute to both energy and economic performance of a CCHP system is proposed. By applying this feed-in tariff policy, the impact on design optimization (power generation unit capacity and operation strategy) and system performance (economic, energy, and matching performance) of a hospital CCHP system used in different climate zones are evaluated and analyzed. In policy one $\left(\mathrm{Pol}_{1}\right)$, no electricity is allowed to be sold. In policy two $\left(\operatorname{Pol}_{2}\right)$, the electricity selling price is constant. In policy three $\left(\mathrm{Pol}_{3}\right)$, the selling price of electricity is proportional to the PER (Primary Energy consumption Ratio) of the system when the PER is not lower than a critical value. Otherwise, the selling price is zero. The results show that $\mathrm{Pol}_{3}$ can ensure both energy and economic performances of CCHP system. The effect of feed-in tariff policy to improve the performance of CCHP system reduces gradually from the cold zone to the hot zone. Multi-criteria decision making results show that $\mathrm{Pol}_{3}$ with reasonable parameters is the best choice in all climate zones except for the hottest zone in this study. When improving PER is attractive, following thermal load operation strategy is the best choice under $\mathrm{Pol}_{3}$. In the hottest zone of this study, little excess
\end{abstract}

\footnotetext{
* Correspondence to: Dr. J.Y Wu, Tel. and Fax: (86-21) 34206776, E-mail: jywu@ sjtu.edu.cn.
} 
electricity would be produced and sold to the grid. Feed-in tariff policy has little help to improve the economic and energy performance in this zone.

Keywords: CCHP system; feed-in tariff policy; system design; different climate zones; operation strategy

\begin{tabular}{|ll|}
\hline Nomenclature & \\
AC & Absorption chiller \\
ATCSR & Annual total cost saving ratio \\
CCHP & Combined cooling, heating and power \\
COP & Coefficient of performance \\
EC & Electric chiller \\
FEL & Following electric load \\
FTL & Following thermal load \\
HPR & Heat to power ratio \\
ICE & Internal combustion engine \\
Min-PLR & Minimum partial load ratio \\
OEF & On-site energy fraction \\
OEM & On-site energy matching \\
OS & Operation strategies \\
PER & Primary energy consumption ratio \\
PGU & Power generation unit \\
SC & Stop condition \\
SHP & Separate heat and power \\
LHV & Low heat value of natural gas $\left(\mathrm{kWh} / \mathrm{m}^{3}\right)$ \\
\hline
\end{tabular}




\begin{tabular}{|c|c|}
\hline Symbols & \\
\hline$C$ & Value of criterion \\
\hline$C c$ & Initial capital cost coefficient $(\$ / \mathrm{kW})$ \\
\hline$C M$ & Maintenance cost coefficient $(\$ / k W h)$ \\
\hline$C p$ & Capacity $(\mathrm{kW})$ \\
\hline$E$ & Electricity energy (kW) \\
\hline$F$ & Fuel $\left(m^{3}\right)$ \\
\hline$f$ & Partial load factor \\
\hline$I$ & Interest rate $(\%)$ \\
\hline$K$ & Proportionality coefficient \\
\hline$n$ & Number \\
\hline$p$ & Price $\left(\$ / \mathrm{kWh}\right.$ or $\left.\$ / \mathrm{m}^{3}\right)$ \\
\hline Pol & Policy \\
\hline pro & project \\
\hline$Q$ & Thermal energy $(\mathrm{kW})$ \\
\hline$R$ & Capital recovery factor \\
\hline$w$ & Weighting factor \\
\hline$\eta$ & Efficiency level \\
\hline Subscrip & \\
\hline$a c$ & Absorption chiller \\
\hline$b$ & Boiler \\
\hline$c$ & Cooling \\
\hline$d$ & Distance \\
\hline$e$ & Electricity \\
\hline$e c$ & Electric chiller \\
\hline$e q$ & Equipment \\
\hline$f$ & Fuel \\
\hline grid & Electricity grid \\
\hline$h$ & Heating \\
\hline$H X$ & Heat exchanger \\
\hline in & Into \\
\hline life & Life \\
\hline out & Out \\
\hline rate & Rate \\
\hline$r h$ & Recovery heat for heating \\
\hline th & Thermal \\
\hline waste & Waste \\
\hline water & Water \\
\hline Superscr & \\
\hline ben & Benchmark \\
\hline ideal & Ideal \\
\hline non-ideal & Non-ideal \\
\hline
\end{tabular}


Nominal

normal

Normal 


\section{Introduction}

Combined cooling, heating, and power (CCHP) systems are becoming more and more popular all over the world because they can help to reduce cost, primary energy, and emission [1]. However, development of CCHP systems is not ideal in many countries because its economic performance is not good enough to attract investment. Various factors would influence the economic performance, such as the supportive policy, the energy prices, the building demands, the initial cost, the electricity market, and the design of CCHP systems. Among them, the supportive policy is one of the most important incentive measures. Economic performance of a CCHP system usually conflicts with its energy performance $[\mathbf{2}, \mathbf{3}]$, therefore, multi-criteria evaluation has attracted more and more attention $[\mathbf{4}, \mathbf{5}]$. As a result, both economic and energy performance should be taken into account when formulating a policy for the generalization of CCHP systems.

During the past decades, various policies and measures have been introduced by different countries to stimulate the development of CCHP system. CHP system support mechanisms of the European countries include tax support, feed-in tariff, certificate scheme, capital grant, and etc. Among them, the most popular mechanism is the feed-in tariff policy. It was used in 16 out of 27 countries [6]. In Germany, several measures have been taken to improve the installation of cogeneration system including duty-free for electricity and gas, subsidy for buying electricity from cogeneration system, and a quota model [1]. In Denmark, feed-in tariff policy not merely helps to improve the share of CHP production, but also incentivizes those systems to operate flexibly [7]. In 2007, all the cogenerators above 5MW were forced to operate under spot market conditions [8]. In United States, some specific incentive programs for CHP system have been initiated by states such as California, New York, 
Massachusetts, and etc [9]. Feed-in tariff policy has been initiated in California. The Federal Energy Regulatory Commission did not preempt this policy, but they approved that the environment externalities, adders for transmission constraints, and multi-tiered rates had been considered by the design of this policy [9]. In Japan, the government promoted the development and installation of CCHP systems through special taxation scheme, investment subsidies and low interest Loans [10]. The total generation capacity of CCHP systems in Japan has increased from $200 \mathrm{~kW}$ in 1986 to $9440 \mathrm{MW}$ in March 2010 [11]. Making support policy is one of the most effective ways to promote CCHP system. An appropriate stimulus policy could help to increase the investment and install capacity of CCHP system. Feed-in tariff is one of the most important policies for promoting the installation and development of CCHP systems. It has a great impact on profitability, sizing, and overall energy efficiency of a project. Besides, electricity selling price influences the investment market of CCHP system [12].

Some literatures have researched the influence of the feed-in tariff policy on the design, operation strategy, and economic performance of CCHP systems. Tichi et al. [13] studied the influence of policies for energy price on the design of CCHP systems in Iran. They pointed out that a higher capacity of CCHP system was preferable when selling electricity to the utility was permitted from an economic point of view. They also concluded that the policies of selling electricity and eliminating subsidies could help to widespread the utilization of CCHP systems. Sanaye and Khakpaay[14] compared the design parameters and performance of CCHP system following different scenarios (selling electricity or not) and different operation strategies. The results showed that the relative annual benefit value in no selling electricity scenario was much smaller than that in selling electricity scenario. 
Siler-Evans et al. [15] evaluated the ability of feed-in tariffs to resist energy price risks. They pointed out that a fixed electricity payment had little effect on risk-resistant, while the energy price risks could be eliminated by a two-part feed-in tariff (one part is for annual capacity, the other part is for the energy which is adjusted with fuel prices). Fragaki [16] studied the conditions for aggregation of CHP plants in the UK electricity market. They found that higher electricity prices could make more profit if some of the produced heat were dissipated. Pade et al. [17] analyzed the relationship among policy support mechanisms, operation strategy and ownership arrangements of micro-CHP system. They stated that different support schemes were appropriate for different countries. Vandewalle and D'haeseleer [18] studied how the gas demand was influenced by the implementation of micro-CHP system. They found that the peak of gas demand would be increased by a low feed-in tariff. From the description above, it can be concluded that the pricing and mechanism of feed-in tariff policy will impact the economic and energy performance of CCHP system a lot.

The feed-in tariff policies could probably be classified into two types based on the present studies. The first type is selling electricity is not permitted. In fact, for CCHP system used in the building, selling electricity is not permitted in many countries and regions in the world, such as China and many other developing countries. The second type is that the determination of the feed-in tariff is not relative with the noneconomic parameters like the energy or environment criteria. The present studies [12-16] [18] often focus on this kind of feed-in tariff policy to improve the economic performance of CCHP system. However, economic performance and energy or environment performance are often in conflict with each other under this kind of policy [16]. Moreover, the original intention of CCHP system is 
energy conservation and emission reduction. So this policy should be improved to be a policy which can ensure both economic and energy or environment performance of CCHP system.

On the other hand, some literatures have focused on the optimization of CCHP system [35-37] and system performance in different climate zones $[4,21]$. In these literatures, the results are achieved only based on a certain feed-in tariff policy (type one or type two described above). The impacts of different feed-in tariff policies are seldom discussed. As presented above, the feed-in tariff policy has a great impact on the economic and energy performance of CCHP system. On the other hand, the effect of feed-in tariff policy on a CCHP system has a great relationship with the amount of excess electricity produced by the system, which is depended on the energy demands of a building. It is said that the effect of feed-in tariff policy may be different in different climate zones. According to the analysis above, it is very necessary to make sure how the feed-in tariff policy influences the optimal design and performance of CCHP system in different climate zones, which is very important for the decision maker to formulate an effective policy.

In this paper, an improved feed-in tariff policy is proposed in this paper. Under this policy, the selling price of electricity is proportional to the primary energy ratio (PER) of the system when the PER is not lower than a critical value. Such kind of policy can relate the economic performance with the energy performance of system. It is the key to ensure both economic and energy performance of the system. Besides, the impacts of different feed-in tariff policies on the optimal design (power generation unit capacity and operation strategy) and performance (economic, energy, and matching performance) of CCHP system in different climate zones are evaluated and compared. Lastly, the feasibility of the policies in different climate zones is also analyzed. 
In the subsequent section, the CCHP system and the building demands in different climate zones are described. Three types of feed-in tariff policy $\left(\mathrm{Pol}_{1}, \mathrm{Pol}_{2}\right.$, and $\left.\mathrm{Pol}_{3}\right)$ are introduced. Then four typical operation strategies are described. Besides, the optimal and decision making method are showed. In section 3, the details of how the feed-in tariff policies impact on the CCHP system are analyzed based on the climate in Shanghai. Then the impacts of these policies on CCHP system in different climate zones are assessed and compared. Lastly, some conclusions and recommendations are offered based on the analysis in this study.

\section{Methods}

\subsection{Energy demands of building and system descriptions}

\subsubsection{Energy demands of building in different climate zones}

In order to evaluate the impact of feed-in tariff policy on CCHP system in different climate zones, the detailed energy demand information in these climate zones should be explored. In this study, the demand data of a hospital in Shanghai with a covered area of $70,488 \mathrm{~m}^{2}$ is chosen as the base scenario.

The hourly energy demands included electricity demand $E_{e}$, cooling demand $Q_{c}$, heating demand $Q_{h}$, and hot water demand $Q_{h \text {,water }}$ These data of energy demands are achieved by the calculation according to the annual metrical data. Then the regional coefficients for different climate zones, affected by different climatic conditions and other factors [32], are employed to calculate the energy demands in other climatic zones, as showed in Eq. (1-4).

$$
\begin{aligned}
& E_{e, i}^{j}=E_{e, i} \cdot f_{e}^{j} \\
& Q_{c, i}^{j}=Q_{c, i} \cdot f_{c}^{j} \\
& Q_{h, i}^{j}=Q_{h, i} \cdot f_{h}^{j}
\end{aligned}
$$




$$
Q_{h, \text { water }, i}^{j}=Q_{h, \text { water }, i} \cdot f_{h, \text { water }}^{j}
$$

where $i$ represents the $i$ th hour in a year; $j$ represents the $j$ th climate zone.

The latitude of Shanghai $\left(121.5^{\circ} \mathrm{E}, 31.2^{\circ} \mathrm{N}\right)$ and Kagoshima $\left(130.3^{\circ} \mathrm{E}, 31.4^{\circ} \mathrm{N}\right)$ are very close to each other. According to ref. [32], the regional coefficients used in this study are showed in Appendix A. It can be seen that the latitudes of these cities change from $26^{\circ} \mathrm{N}$ to $43^{\circ} \mathrm{N}$, while climates change from "warm summer and cold winter" to "hot summer and warm winter". In Fig. 1, the heating demand, cooling demand, and electric demand of building in different climate zones are presented. The range of Heating to Power ratio (HtoP) is $0.16 \sim 1.50$. And the range of Cooling to Power ratio (CtoP) is $0.23 \sim 0.66$.

\subsubsection{System descriptions}

In Fig.2, energy flows of a CCHP system are shown. The power generation unit (PGU) is an internal combustion engine (ICE) in this study. The fuel gas is put into PGU to produce electricity. The heat recovery system is used to recover the waste heat from PGU. The absorption chiller produces cooling by using the recovered heat. In summer, thermal energy is preferentially used for cooling rather than supplying domestic hot water. If cooling demand cannot be met by the absorption chiller, the surplus part would be satisfied by an electric chiller. In winter, if the recovery heat is less than the heating demand, the surplus would be satisfied by a boiler. The total electricity demand is equal to the sum of electricity used by electric chiller and electricity demand of the building. When putting electricity into the grid is prohibited, the PGU can never generate more power than the total electricity demand. In this case, the electricity demand which cannot be met by the PGU would be satisfied by the grid. However, if selling electricity is permitted, the excess electricity can be put into the grid when PGU generates 
more power than the total electricity demand. The detail of energy flows for the CCHP systems has been presented by Zheng et al. [20]. The details of energy performance of the absorption chiller and the ICE are presented in Appendix B.

\subsection{Evaluation criteria}

\subsubsection{Economic criterion}

The economic performance is assessed by the annual total cost saving ratio (ATCSR) [21]. It can be calculated as:

$$
\mathrm{ATCSR}=\frac{\mathrm{ATC}_{\mathrm{SHP}}-\mathrm{ATC}_{\mathrm{CCHP}}}{\mathrm{ATC}_{\mathrm{SHP}}} \times 100 \%
$$

where the $\mathrm{ATC}_{\mathrm{SHP}}$ and $\mathrm{ATC}_{\mathrm{CCHP}}$ can be calculated as:

$$
\begin{aligned}
\mathrm{ATC}_{\mathrm{SHP}} & =R \cdot \sum_{k=1}^{n_{1}}\left(C p_{k} C c_{k, e q}\right)+\sum_{i=1}^{365} \sum_{k=1}^{24}\left(\left(E_{i k}+\frac{Q_{i k, c}}{\mathrm{COP}_{e c}}\right) p_{e, \text { in }}+\frac{Q_{i k, h}}{\eta_{b}} p_{f 1}\right) \\
& \mathrm{ATC}_{\mathrm{CCHP}}=R \cdot \sum_{k=1}^{n_{2}}\left(C p_{k} C c_{k, \text { eq }}\right)+C M_{I C E} \cdot \sum_{i=1}^{365} \sum_{k=1}^{24} E_{i k, p g u} \\
& +\sum_{i=1}^{365} \sum_{k=1}^{24}\left(E_{i k, g r i d, \text { in }} p_{e, \text { in }}-E_{i k, \text { grid,out }} p_{e, \text { out }}+F_{i k, b} p_{f 1}+F_{i k, p g u} p_{f 2}\right)
\end{aligned}
$$

where $R$ is the capital recovery factor and the calculation formula is presented in Appendix $\mathbf{B} ; n_{l}$ is the number of equipments for the SHP system; $C p$ is the capacity of equipment; $C c_{e q}$ is the capital cost of equipment; $C M_{\text {ICE }}$ is the maintenance cost coefficient; $n_{2}$ is the number of equipments for the CCHP system; $p_{f 2}$ is the price of natural gas for CCHP system; $p_{e, i n}$ and $p_{e, o u t}$ are the price of electricity bought from and sold out to the grid; $p_{f l}$ is the price of natural gas for the boiler; $E$ is the electrical demand; $Q_{h}$ is the heating demand; $Q_{c}$ is the cooling demand. It is assumed that there is no time-based variation in all the costs except for the capital cost of equipments. The main parameters used in the evaluation are listed in Table 1. The capital cost and maintenance cost coefficient of ICE are 
presented in Appendix B. The capital cost of the absorption chiller is showed in Appendix B. The unit prices of the other facilities are showed in Table 2.

\subsubsection{Energy criterion}

The energy performance is assessed by the primary energy consumption ratio (PER) [4]. It can be calculated from the following Eq. (8):

$$
\mathrm{PER}=\frac{E_{p g u}+Q_{a c}+Q_{r h}}{F_{p g u}} \times 100 \%
$$

where $E_{p g u}$ is the electricity generated by the PGU; $Q_{r h}$ is the recovery heat used to satisfy the heat demand; $Q_{a c}$ is the cooling from the absorption chiller.

\subsubsection{Matching criterion}

'On-site Energy Matching (OEM)' and 'On-site Energy Fraction (OEF)' [22] are used to assess the matching performance between the system and the building. The OEM is defined as the ratio of on-site generated energy used for the demand to total on-site generated energy, while the OEF is defined as the ratio of on-site generated energy used to satisfy the demand to the total demand [23].Considering that heating and cooling are often not needed at the same time, their importance at a specific time is different. They can be calculated as:

$$
\begin{aligned}
\mathrm{OEM} & =\left(w_{3} \cdot \mathrm{OEM}_{e}+w_{4} \cdot \mathrm{OEM}_{t h}\right) \times 100 \% \\
& =\left(w_{3} \cdot \mathrm{OEM}_{e}+w_{4} \cdot\left(\mathrm{OEM}_{h}+\mathrm{OEM}_{c}\right) / 2\right) \times 100 \% \\
\mathrm{OEF} & =\left(w_{1} \cdot \mathrm{OEF}_{e}+w_{2} \cdot \mathrm{OEF}_{t h}\right) \times 100 \% \\
& =\left(w_{1} \cdot \mathrm{OEF}_{e}+w_{2} \cdot\left(\mathrm{OEF}_{h}+\mathrm{OEF}_{c}\right) / 2\right) \times 100 \%
\end{aligned}
$$

where $\mathrm{OEM}_{e}, \mathrm{OEM}_{h}, \mathrm{OEM}_{c}, \mathrm{OEF}_{e}, \mathrm{OEF}_{h}$, and $\mathrm{OEF}_{c}$ can be calculated by the following equations:

$$
\mathrm{OEM}_{e}=\frac{E_{p g u}-E_{g r i d, o u t}-E_{e c, p g u}}{E_{p g u}}
$$




$$
\begin{gathered}
\mathrm{OEM}_{h}=\frac{Q_{r h}}{Q_{r h}+Q_{h, \text { waste }}} \\
\mathrm{OEM}_{c}=\frac{E_{e c, p g u} \cdot C O P_{e c}+Q_{a c}}{E_{e c, p g u} \cdot C O P_{e c}+Q_{a c}+Q_{c, \text { waste }}} \\
\mathrm{OEF}_{e}=\frac{E_{p g u}-E_{g r i d, o u t}-E_{e c, \text { ICE }}}{E} \\
\mathrm{OEF}_{c}=\frac{E_{e c, p g u} \cdot C O P_{e c}+Q_{a c}}{Q_{c}}
\end{gathered}
$$

where $E_{e c \text { pgu }}$ is the electricity produced by PGU for electricity chiller; $Q_{h, \text { waste }}$ is the waste heating energy; $Q_{c \text {,waste }}$ is the waste cooling energy. For a building, thermal and electricity demands are equally important, because both of them must be covered by any energy resource to achieve the building function. These two evaluation criteria are used to evaluate the matching performance between energy supply of CCHP system and demands of the building. In this paper, the function of OEM is used to evaluate how much on-site generated energy is exported or wasted. And the function of OEF is used to evaluate how much demands are covered by the on-site generated energy. Therefore, all the four weighting factors $w_{i}$ are set to be 0.5 in this study.

\subsection{Feed-in tariff policies}

In order to make some suggestions for the feed-in tariff policy in different climate zones, three policies are evaluated in this study.

$\boldsymbol{P o l}_{1}$ : Selling electricity is not permitted.

$\boldsymbol{P o l}_{2}$ : Selling electricity is permitted. The selling price is constant. It is calculated as:

$$
p_{e, \text { out }}=p_{e, \text { out }}^{\text {ben }}
$$


where $p_{e, \text { out }}^{\text {ben }}$ is the benchmark feed-in tariff.

$\boldsymbol{P o l}_{3}$ : This policy is proposed to ensure both energy and economic performance of CCHP system at a reasonable level. Selling electricity is permitted. The selling price increases with the increase of PER of the system when the PER is not lower than a critical value PER ${ }^{\text {ben }}$. Otherwise the selling price is zero. The feed-in tariff for $\mathrm{Pol}_{3}$ is calculated as:

$$
p_{e, \text { out }}=\left\{\begin{array}{cl}
0 & \mathrm{PER}<\mathrm{PER}^{\text {ben }} \\
\left(1+K\left(\mathrm{PER}-\mathrm{PER}^{\text {ben }}\right)\right) p_{e, \text { out }}^{\text {ben }} & \mathrm{PER} \geq \mathrm{PER}^{\text {ben }}
\end{array}\right.
$$

where $\mathrm{K}$ is the proportionality coefficient for $\mathrm{Pol}_{3} . \mathrm{K}$ reflects the strength of the policy supporting for a higher PER. For example, if $K$ is equal to 1 , the feed-in tariff $P_{e, \text { out }}$ increases $1 \%$ as $\left(\mathrm{PER}-\mathrm{PER}^{\text {ben }}\right)$ is increased $1 \%$. If $K$ is equal to 10 , the feed-in tariff increases $10 \%$ as $\left(\mathrm{PER}-\mathrm{PER}^{\text {ben }}\right)$ is increased $1 \%$. With the increase of $K$, more feed-in tariff would be increased with per unit increase of $\left(\mathrm{PER}-\mathrm{PER}^{\text {ben }}\right)$.

\subsection{Operation strategies descriptions}

The choice of operation strategy is governed by factors including the utilized fuel cost, availability of a storage system for excess electricity and thermal energy produced, and the permission of selling excess electricity [24]. Therefore, the choice of operation strategy may be different for different feed-in tariff policies. Four operation strategies $\left(\mathrm{OS}_{1}, \mathrm{OS}_{2}, \mathrm{OS}_{3}\right.$, and $\left.\mathrm{OS}_{4}\right)$ are employed to evaluate the impacts of feed-in tariff policy, which are showed in Fig. 3. The curve $l$ represents a perfect match between the thermal load and electrical load of a PGU. The curve $l$ is given in the power to heat ratio performance of PGU at different partial load. Two major types of load points exist among the annual building loads: Load point $L_{1}$ above the curve $l$ and Load point $L_{2}$ below the curve $l$. Obviously, the position of the load point (above or below the curve $l$ ) depends on the capacity of PGU, electricity load, and thermal 
load. Besides, electricity and thermal loads change during the year, and capacity of PGU changes during the sizing optimization process. Therefore, both of these situations would exist during annual performance of the system.

These operation strategies consist of four factors: following thermal load (FTL) strategy, following electric load (FEL) strategy, minimum partial load ratio (Min-PLR), and stop condition (SC).

FTL strategy: When the FTL is implemented, the thermal demand will be fulfilled first. If the CCHP system yield is not sufficient to meet electricity demand, additional electricity will be supplied by the grid. The situation that the electricity produced by PGU exceeds the electric demand exists in the operation process under FTL strategy. When selling electricity is not allowed, this situation is forbidden. At this time, the PGU should be stopped. If selling electricity is allowed, producing excess electricity is allowed. For FTL strategy, the least waste heat would be produced while some of electricity may be sold to the grid.

FEL strategy: When the FEL is implemented, the electricity demand will be satisfied preferentially. If the recovery heat is not sufficient, the additional thermal energy will be supplied by an auxiliary boiler. Once excess thermal energy is produced, it will be wasted. In this situation, the least excess electricity would be produced while some of the heat may be wasted.

Min-PLR: Min-PLR is an artificial parameter. In the operation process, the part load ratio of PGU should not be lower than Min-PLR. When Min-PLR is equal to 1, it means that the PGU would run at full load once it is up and running. According to the data of ref. [27], the range of Min-PLR is 0.4 to 1 in this study. The larger the Min-PLR, the more excess electricity and waste heat would be produced. 
Stop condition (SC): 1) The PGU is stopped when the operation cost is more than that of the SHP system for the same production. 2) The partial load ratio of PGU should not be lower than Min-PLR. Otherwise PGU would stop. 3) When selling electricity is not allowed, once excess electricity is produced, the PGU would be stopped.

The solid line between Min-PLR point and Full Load point represents the operating range of PGU. The role of an operation strategy is to determine the path from the load point to the operation point. For example the path $L_{l} O_{l}$ in Fig. 3(a), it is determined by the FTL strategy: the produced thermal energy is equal to the thermal load, but the produced electricity is less than the electrical load. The characteristic of these operation strategies can be deduced based on the scope of ref. [20]. The energy production performance of CCHP system is different when it operates under different operation strategies. In Table 3, the characteristics of energy production for these four operation strategies are summarized.

\subsection{Optimization and decision making}

\subsubsection{Optimization method}

The optimization method in this paper is showed in Fig. 4. This method is used based on different feed-in tariff policies. The operation strategy could strongly influence the optimal capacity of PGU. Therefore, the capacity of PGU should be optimized under different operation strategies, respectively. The optimization algorithm used in this paper is the golden section algorithm. There are two kinds of constraints in the optimization process: facility constraints and energy balance constraints. The details of energy balance constraints are presented in the previous work [20]. For facility constraints, the capacity of absorption chiller is determined by the rated thermal output of PGU and the COP of the 
chiller; the capacity of electric chiller is determined by maximum cooling demand of the building; the capacity of boiler is determined by maximum heating demand (heating and hot water demand) of the building. In order to illustrate how a certain factor influences the performance of the system, the values of the other factors would be fixed (In subsection 3.1 -3.3). In subsection 3.4, the optimal results are showed to analyze the impacts of feed-in tariff policy on design and performance of CCHP system.

\subsubsection{Decision making}

As the analysis above, a good feed-in tariff policy should ensure both economic and energy performance of the system. Therefore, both ATCSR and PER should be employed to decide which policy is the best. In this paper, TOPSIS (Technique for Order of Preference by Similarity to Ideal Solution) $[\mathbf{3 3}, \mathbf{3 4}, \mathbf{3 8}]$ is employed for decision making. The method used to normalize the value of evaluation criteria is:

$$
C_{i j}^{n o r m a l}=\frac{C_{i j}}{\sqrt{\sum_{j=1}^{m} C_{i j}^{2}}}
$$

where $C_{i j}$ is the magnitude of $i$ th evaluate criterion of $j$ th sample; $m$ is the number of samples. Then the ideal value $C_{i}^{\text {ideal }}$ is defined by the best value of all samples, while the non-ideal value $C_{i}^{\text {non-ideal }}$ is defined by the worst value. Then distances of each sample from the ideal $d_{j+}$ and non-ideal $d_{j-}$ can be determined as follows:

$$
\begin{gathered}
d_{j+}=\sqrt{\sum_{i=1}^{k}\left(w_{i}\left(C_{i j}^{\text {normal }}-C_{i}^{\text {ideal }}\right)\right)^{2}} \\
d_{j-}=\sqrt{\sum_{j=1}^{k}\left(w_{i}\left(C_{i j}^{\text {normal }}-C_{i}^{\text {non-ideal }}\right)\right)^{2}}
\end{gathered}
$$

where $k$ is the number of evaluation criteria; $w_{i}$ is the weight factor for $i$ th criterion. In this paper, the values of weight factors are determined by the entropy method [34]. Then a $C l_{j}$ parameter is defined as follow: 


$$
C l_{j}=\frac{d_{j-}}{d_{j+}+d_{j-}}
$$

$\mathrm{Cl}$ is a positive index.

\section{Results and Discussion}

\subsection{Impacts of allowing selling electricity on CCHP system performance (Zone 5)}

The effect of selling electricity on the CCHP system performance of different operation strategies is analyzed in this section. Two situations are compared. One is that selling electricity is not permitted $\left(\mathrm{Pol}_{l}\right)$. The other is that selling electricity is permitted and the selling price is $0 \mathrm{\$} / \mathrm{kWh}\left(\mathrm{Pol}_{2}\right.$ and $\left.\mathrm{Pol}_{3}\right)$. In this subsection, the capacity of ICE and Min-PLR are set as $1000 \mathrm{~kW}$ and 0.4 , respectively.

Fig. 5(a) presents the ATCSR, PER, OEF, and OEM of CCHP system for different operation strategies under $\mathrm{Pol}_{1}$. The ATCSRs of $\mathrm{OS}_{3}$ and $\mathrm{OS}_{4}$ are $-1.2 \%$ and $-0.4 \%$ respectively, which means they cannot save cost compared with SHP system. (The ATCSRs of OS 1 and $\mathrm{OS}_{2}$ of SHP system are just $3.7 \%$ and $4.5 \%$, respectively.) The operation time of CCHP system is significantly limited by forbidding selling electricity. Therefore, the OEF of the CCHP system is small, which means the CCHP system makes a small contribution to meet the demands of the building. On the other hand, the PERs of $\mathrm{OS}_{1}$ and $\mathrm{OS}_{3}$ are better than those of $\mathrm{OS}_{2}$ and $\mathrm{OS}_{4}$. The OEMs of $\mathrm{OS}_{1}$ and $\mathrm{OS}_{3}$ almost reach $100 \%$, which represents almost all the energy produced by the CCHP system can be used to satisfy the energy demand of the building. From Fig. 5(a), it can be concluded that $\mathrm{OS}_{1}$ and $\mathrm{OS}_{2}$ are the better operation strategies compared with $\mathrm{OS}_{3}$ and $\mathrm{OS}_{4}$ under $\mathrm{Pol}_{1}$

Fig.5 (b) shows the ATCSR, PER, OEF, and OEM of CCHP system for different operation strategies under $\mathrm{Pol}_{2} \& \mathrm{Pol}_{3}$ with the $p_{e, \text { out }}^{\text {ben }}$ of $0 \$ / \mathrm{kWh}$. According to Eq. (17) and Eq. (18), electricity selling prices of $\mathrm{Pol}_{2}$ and $\mathrm{Pol}_{3}$ are equal when the $p_{e, \text { out }}^{\text {ben }}$ is equal to $0 \mathrm{\$} / \mathrm{kWh}$. Besides, 
parameters $\mathrm{K}$ and $\mathrm{PER}^{\text {ben }}$ in $\mathrm{Pol}_{3}$ have no effect. As a result, the performances of CCHP system under $\mathrm{Pol}_{2}$ and $\mathrm{Pol}_{3}$ are the same. By comparing Fig. 5(b) with Fig. 5(a), it can be observed that the economic performance of $\mathrm{Pol}_{2}$ is better than that of $\mathrm{Pol}_{1}$ even if the selling price is zero. The average increase of ATCSR is $5.35 \%$. When selling electricity is permitted, the operation time of CCHP system can be prolonged and more energy demands of the building will be satisfied by CCHP system. For this reason, the OEFs for all the operation strategies increase a lot. At the same time, the OEMs of $\mathrm{OS}_{3}$ and $\mathrm{OS}_{4}$ will have a slight decrease, while the OEMs of $\mathrm{OS}_{1}$ and $\mathrm{OS}_{2}$ almost remain the same. The foremost reason is that the excess electricity sold to the grid of $\mathrm{OS}_{1}$ and $\mathrm{OS}_{2}$ is much smaller than that of $\mathrm{OS}_{3}$ and $\mathrm{OS}_{4} \cdot \mathrm{OS}_{2}$ is the best strategy from economic performance point of view when the feed-in tariff is not attractive. But $\mathrm{OS}_{3}$ or $\mathrm{OS}_{4}$ would become a better choice with the increase of the selling price. From the analysis above, it can be concluded that allowing selling electricity could improve the economic performance of CCHP system even if the selling price is equal to zero.

\subsection{Analysis of CCHP system performance under $\mathrm{Pol}_{2}$ (Zone 5)}

When $p_{e, \text { out }}^{\text {ben }}$ is equal to $p_{e, \text { in }}$, ICE capacity would be chosen to be $1275 \mathrm{~kW}$ for the highest ATCSR(Min-PLR=0.4). The comparison of the performance of CCHP system between ATCSR optimization and PER optimization when ICE capacity is equivalent to $1275 \mathrm{~kW}$ is presented in Fig. 6. When optimizing ATCSR, PER and OEM decrease with the increase of $p_{e, \text { out }}^{\text {ben }}$. Conversely, ATCSR and OEF increase with the increase of $p_{e, \text { out }}^{\text {ben }}$. With the increase of $p_{e, \text { out }}^{\text {ben }}$, CCHP system will produce more excess electricity and waste heat to improve energy contribution for the building and economic performance. The PER, OEF, and OEM remain the same values until $p_{e, \text { out }}^{\text {ben }} / p_{e, \text { in }}$ increases to be 0.727 . It can be deduced that selling electricity is not attractive when $p_{e, \text { out }}^{\text {ben }}$ is at this level. From Fig. 6, it 
can also be observed that $p_{e, \text { out }}^{\text {ben }}$ has no effect on the PER, OEF, and OEM when optimizing PER. The optimized PER is much higher than that of ATCSR optimization. When $p_{e, \text { out }}^{\text {ben }} / p_{e, \text { in }}$ is equal to 1 , the optimized PER is $75.8 \%$. While the PER of optimizing ATCSR is only $60.5 \%$. It infers that the policy with a fixed selling price $\left(\mathrm{Pol}_{2}\right)$ may reduce the net energy efficiency of the CCHP system, let alone making improvements.

\subsection{Analysis of CCHP system performance under $\mathrm{Pol}_{3}$ (Zone 5)}

There are two important parameters in $\mathrm{Pol}_{3}: \mathrm{PER}^{\text {ben }}$ and $K$. The effect of these two parameters is discussed in this section.

\subsubsection{Impact of PER ${ }^{\text {ben }}$ on $\mathrm{Pol}_{3}(K=0)$}

Capacity of ICE is fixed at $1275 \mathrm{~kW}$ and $K$ is fixed at zero in this subsection. Fig. 7 presents the impact of $p_{e, \text { out }}^{\text {ben }}$ on PER of the CCHP system as a function of PER ${ }^{b e n}$ when optimizing ATCSR under $\mathrm{Pol}_{3}$. The PER ${ }^{\text {ben }}$ has a great impact on PER. The PER would decrease to approach the PER ${ }^{\text {ben }}$ with the increase of $p_{e, \text { out }}^{\text {ben }}$. No matter how high the $p_{e, \text { out }}^{\text {ben }}$ is, the PER of CCHP system would not be lower than $\mathrm{PER}^{\text {ben }}$. It is stated that the value of the minimum PER could be controlled by setting $\mathrm{PER}^{\text {ben }}$. When the benefits bought by selling electricity is less than the marginal operation cost of producing more energy, the PER would not be influenced by the $p_{e, \text { out }}^{\text {ben }}$. The points, where PER begins to decrease, are different for different $\mathrm{PER}^{\text {ben }}$. It is deduced that the equilibrium point of marginal benefit brought by selling electricity and the marginal operation cost for producing more energy is different for different situations. When $\mathrm{PER}^{\text {ben }}$ is equal to $71.5 \%$ and $75 \%$, the PER of CCHP system remains the same with the increase of $p_{e, \text { out }}^{\text {ben }}$. There are two reasons leading to this phenomenon. Firstly, the PER would not be lower than PER ${ }^{\text {ben }}$. Secondly, the effect of Min-PLR on performance of CCHP system is 
so significant that little increase of Min-PLR would make PER reduce to be lower than PER ${ }^{\text {ben }}$ (the optimization precision of Min-PLR is 0.0001 ). When Cap $_{\text {ICE }}$ is equal to $1275 \mathrm{~kW}$, the PER remains the same as the increase of $p_{e, \text { out }}^{\text {ben }}$ once $\mathrm{PER}^{\text {ben }}$ is higher than $71.5 \%$.

Fig. 8 presents the comparison of ATCSR and PER between $\mathrm{Pol}_{2}$ and $\mathrm{Pol}_{3}$ when optimizing ATCSR. The ATCSR of $\mathrm{Pol}_{3}$ is lower than that of $\mathrm{Pol}_{2}$. But the PER of $\mathrm{Pol}_{3}$ is better than that of $\mathrm{Pol}_{2}$. Compared with $\mathrm{Pol}_{2}$, when CCHP system operates under $\mathrm{Pol}_{3}$, less waste heat and excess electricity would be produced and fewer demands of the building are satisfied by CCHP system. $\mathrm{Pol}_{3}$ can control the minimum PER of the CCHP system reliably when the $p_{e, \text { out }}^{\text {ben }}$ is high. As this function of $\mathrm{Pol}_{3}$, the ATCSR of CCHP system can be improved through increasing the feed-in tariff while the PER can be ensured at a reasonable level.

\subsubsection{Impact of $\mathrm{K}_{\text {on }} \mathrm{Pol}_{3}\left(\mathrm{PER}^{\text {ben }}=70 \%\right)$}

When $\mathrm{K}$ is equal to zero, $\mathrm{Pol}_{3}$ could only make the CCHP system operate at the level of PER ${ }^{\text {ben }}$, but not improving PER to the highest possible value. The effect of $K$ is the focus in this section. The $p_{e, \text { out }}^{\text {ben }} / p_{e, \text { in }}$ and $\mathrm{PER}^{\text {ben }} \quad$ are equal to 0.848 and $70 \%$ respectively in this section.

Fig. 9 describes the impact of $K$ on ATCSR as a function of ICE capacity when optimizing ATCSR under $\mathrm{Pol}_{3}$. It can be observed that the influence of $K$ on ATCSR increases with the increment of ICE capacity. When $K$ is small, the increment of PER is small. The increment of ATCSR is so small that it may not be attractive for the system to improve PER. However, when $K$ is too large, the CCHP system would operate straight for PER. At this time, the energy production of the CCHP system would be far below its full potential to satisfy energy demandsof the building. Then the amount of energy saving 
may be decreased, although the PER is high. Through the analysis above, it can be concluded that $K$ should be determined in a reasonable range.

\subsection{Impacts of feed-in tariff policies on CCHP system in different climate zones}

According to the analysis above, four specific policies are employed to analyze the impacts of feed-in tariff policies on CCHP system in different climate zones. The parameters setting of these policies are: Pol $_{2}: p_{e, \text { out }}^{\text {ben }} / p_{e, \text { in }}=0.848 ;$ Pol $_{3}^{a}: p_{e, \text { out }}^{\text {ben }} / p_{e, \text { in }}=0.848, \mathrm{PER}^{\text {ben }}=70 \%, K=0 ;$ Pol $_{3}^{b}: p_{e, \text { out }}^{\text {ben }} / p_{e, \text { in }}$ $=0.848, \mathrm{PER}^{b e n}=70 \%, K=5$. The economic performance, energy performance, selection of prime mover capacity, selection of operation strategies, and the ratio of $E_{\text {grid,out }}$ to total electricity demand of CCHP system in different climate zones under different feed-in tariff policies are showed in Fig. 10. Because the user is going to select the solution with the best economic performance, all these results are determined by optimizing the economic performance (ATCSR).

In economic and energy performance aspects, the feed-in tariff policy has a greater positive effect in the climate zone which has larger heating demand, as show in Fig. 10(a) and Fig. 10(b). The reason is that more heating demand could be covered by CCHP system when selling electricity is allowed. $\mathrm{Pol}_{2}$ can help to improve economic performance with the sacrifice of energy performance. However, $\mathrm{Pol}_{3}{ }^{b}$ can help to improve both economic and energy performance. These two conclusions could be applied to the other climate zones except for Zone 6, as show in Fig. 10(a) and Fig. 10(b). In Zone 6, thermal demand is small and cooling demand shares a large part of it. What's more, the coefficient of single-effect absorption chiller is low (around 0.7). As a result, the PER of CCHP system in Zone 6 is hard to reach $70 \%$. Then it can be deduced that $\mathrm{Pol}_{3}$ cannot make a positive effect in Zone 6 when PER ${ }^{\text {ben }}$ is set greater than $70 \%$. 
The feed-in tariff policy has a significant impact on the design of prime mover capacity, as show in

Fig. 10(c). When selling electricity is not allowed, capacities of prime mover in different climate zones are seldom different. However, the design capacity of prime mover decreases a lot from Zone 1 to Zone 6 when selling electricity is allowed.

The impact of feed-in tariff policy on operation strategy can be seen in Fig. 10(d) and Fig. 10(e). Under $\mathrm{Pol}_{1}, \mathrm{OS}_{2}$ is selected for avoiding generating excess electricity in all climate zones except for Zone 6. Under $\mathrm{Pol}_{2}, \mathrm{OS}_{4}$ is selected for all climate zones. Besides, the Min-PLR is set higher than $70 \%$. It means that $\mathrm{Pol}_{2}$ with an attractive feed-in tariff would make CCHP system operate for selling electricity and neglect the efficiency of the system in all climate zones. Under $\mathrm{Pol}_{3}{ }^{a}$, the system is operated to produce electricity as much as possible at the condition of reaching the $\mathrm{PER}^{\text {ben }}$. As a consequence, $\mathrm{OS}_{4}$ is selected in Zone 1, Zone 2 and Zone 3; and $\mathrm{OS}_{3}$ is selected in Zone 4 and Zone 5. Under $\mathrm{Pol}_{3}{ }^{b}, \mathrm{OS}_{3}$ and low Min-PLR are selected for high energy efficiency of the system in all climate zones except for Zone 6. In Zone 6, $\mathrm{OS}_{4}$ is selected for these four specific policies. Besides the reason in this subsection above, the other reason is that the cooling demand could not be covered by the recovery heat and some electricity (not included in electricity demand) is needed for dividing the electric chiller. Therefore, $\mathrm{OS}_{4}$ could help to cover energy demands with a better economic performance in Zone 6.

The ratio of $E_{\text {grid,out }}$ to the total electricity demand decreases when climate zone changes from Zone 1 to Zone 6, as show in Fig. 10(f). From the view point of energy saving, the electricity sent to the grid from CCHP system should be with high efficiency energy. However, under $\mathrm{Pol}_{2}$, the CCHP system operates with the maximum electricity sold to the grid but the lowest PER. Obviously, this is 
unreasonable. Therefore, it suggests that some conditions should be appended for selling electricity to the grid. These conditions can be the limitation of electricity sold to the grid or the guarantee of high energy efficiency like $\mathrm{Pol}_{3}$. These conditions should be determined based on different climate zones.

The comprehensive assessment of feed-in tariff policies in different climate zones is showed in Fig. 11. Based on these 24 samples, the weight factors of ATCSR and PER used in Eq. (20-21) are 0.497 and 0.503 , respectively. It can be found that $\mathrm{Pol}_{3}{ }^{b}$ is the best choice in all climate zones except for Zone 6. The differences among $\mathrm{Pol}_{2}, \mathrm{Pol}_{3}{ }^{a}$ and $\mathrm{Pol}_{3}{ }^{b}$ are reduced gradually from the cold zone to the hot zone. The effect of feed-in tariff policy to improve the performance of CCHP system reduces from the cold zone to the hot zone. In Zone 6, the effect of selling electricity is little.

\section{Conclusions}

This paper evaluated and analyzed the impacts of feed-in tariff policies $\left(\mathrm{Pol}_{1}, \mathrm{Pol}_{2}\right.$, and $\left.\mathrm{Pol}_{3}\right)$ on the performance and design of CCHP system built in different climate zones. For $\mathrm{Pol}_{1}$, no electricity is allowed to be sold. For $\mathrm{Pol}_{2}$, the electricity selling price is constant. For $\mathrm{Pol}_{3}$, the electricity selling price is proportional to the PER of the system when the PER is not lower than a critical value. Otherwise the selling price is zero. Some conclusions can be achieved by the results and analyses above:

(1) For $\mathrm{Pol}_{3}$, the efficiency of CCHP system can be guaranteed when a minimum PER is set for getting the excess electricity payment and the system could reach this minimum PER. It can ensure both energy and economic performance of CCHP system. The larger the coefficient $K$ is, the more attractive to improve the energy efficiency of the system.

(2) The feed-in tariff policy has a greater positive effect in the cold zone than in the hot zone. 
$\mathrm{Pol}_{3}^{b}\left(p_{e, \text { out }}^{\text {ben }} / p_{e, \text { in }}=0.848, \mathrm{PER}^{\text {ben }}=70 \%, K=5\right)$ is the best choice in all climate zones except for Zone 6. When selling electricity is not allowed, capacities of the prime mover in different climate zones are seldom different and FEL operation strategy is the best choice in most of the time. However, the capacity decreases a lot from cold zone to hot zone when selling electricity is allowed. When improving PER is attractive, FTL operation strategy is the best choice for most of the time under $\mathrm{Pol}_{3}$.

(3) In the hot zone, where the PER of CCHP system is hard to reach $70 \%$ and the cooling demand could not be covered by the recovery heat and some electricity (not included by electricity demand) is needed for driving electric chiller, seldom electricity is needed to sell to the grid. Feed-in tariff policy has little help to improve the economic performance. At this time, the major goal of the system is to cover the energy demand and $\mathrm{OS}_{4}$ is the best choice.

In real applications, $\mathrm{Pol}_{3}$ can be used by setting the value of $p_{e, \text { out }}^{\text {ben }} / p_{e, \text { in }}$, $\mathrm{PER}^{\text {ben }}$, and $K$ to make the user operate the CCHP system considering both energy and economic performance. Based on the analyses of this paper, the suggestive values are $0.848,70 \%$, and 5 , respectively. The stimulus effect of this policy on the development of CCHP system is gradually weakened from the cold zone to the hot zone. It is preferable used in the cold zone. Under this policy, FTL strategy is preferable used and Min-PLR should be set as a low value. Following these instructions, decision maker can formulate an effective feed-in tariff policy and the operation strategy industrial standard for stimulating the development of CCHP system based on the climate zone. 


\section{Acknowledgements}

This work was supported by National Science Foundation of China under the contract No.

5151101162 and The Walt Disney Company (Shanghai) Limited.

Appendix A. Regional coefficients for calculating the annual energy consumptions [32].

\begin{tabular}{|c|c|c|c|c|c|c|c|}
\hline \multirow{2}{*}{$\begin{array}{l}\text { Climate } \\
\text { Zone }\end{array}$} & \multirow{2}{*}{$\begin{array}{l}\text { Representative } \\
\text { city }\end{array}$} & \multirow[t]{2}{*}{ Position } & \multirow[t]{2}{*}{ Climate } & \multicolumn{4}{|c|}{ Regional coefficients } \\
\hline & & & & $\begin{array}{l}\text { Electricity } \\
f_{e}\end{array}$ & $\begin{array}{l}\text { Cooling } \\
f_{c}\end{array}$ & $\begin{array}{l}\text { Heating } \\
f_{h}\end{array}$ & $\begin{array}{l}\text { Hot water } \\
f_{h, \text { water }}\end{array}$ \\
\hline Zone 1 & Sapporo & $\begin{array}{l}43^{\circ} \mathrm{N} \\
141^{\circ} \mathrm{E}\end{array}$ & $\begin{array}{l}\text { Warm summer and } \\
\text { cold winter }\end{array}$ & 0.89 & 0.42 & 3.43 & 1.21 \\
\hline Zone 2 & Hachinohe & $\begin{array}{l}40^{\circ} \mathrm{N} \\
141^{\circ} \mathrm{E}\end{array}$ & $\begin{array}{l}\text { Warm summer and } \\
\text { cold winter }\end{array}$ & 1.00 & 0.58 & 2.00 & 1.14 \\
\hline Zone 3 & Sendai & $\begin{array}{l}38^{\circ} \mathrm{N} \\
140^{\circ} \mathrm{E}\end{array}$ & $\begin{array}{l}\text { Very warm summer } \\
\text { and cool winter }\end{array}$ & 1.00 & 0.75 & 2.00 & 1.11 \\
\hline Zone 4 & Tokyo & $\begin{array}{l}35^{\circ} \mathrm{N} \\
135^{\circ} \mathrm{E}\end{array}$ & $\begin{array}{l}\text { Hot summer and } \\
\text { cool winter }\end{array}$ & 1.11 & 0.83 & 1.43 & 1.05 \\
\hline Zone 5 & Shanghai & $\begin{array}{l}30^{\circ} \mathrm{N} \\
122^{\circ} \mathrm{E}\end{array}$ & $\begin{array}{l}\text { Hot summer and } \\
\text { cool winter }\end{array}$ & 1.00 & 1.00 & 1.00 & 1.00 \\
\hline Zone 6 & Naha & $\begin{array}{l}26^{\circ} \mathrm{N} \\
127^{\circ} \mathrm{E}\end{array}$ & $\begin{array}{l}\text { Hot summer and } \\
\text { warm winter }\end{array}$ & 1.00 & 1.25 & 0.14 & 0.88 \\
\hline
\end{tabular}

\section{Appendix B. The parameters of ICE and single-effect absorption chiller}

The parameters of ICE used throughout this study are functions of ICE capacity $C p_{\text {ICE. The electrical }}$ efficiency at part loads, nominal electrical efficiency, recovery thermal efficiency at part loads and nominal recovery thermal efficiency of the ICE can be estimated as[26, 27]:

$$
\begin{gathered}
\eta_{e, \mathrm{ICE}}=\left(0.1024\left(\frac{E_{\mathrm{ICE}}}{C p_{\mathrm{ICE}}}\right)^{3}-0.7332\left(\frac{E_{\mathrm{ICE}}}{C p_{\mathrm{ICE}}}\right)^{2}+1.0155\left(\frac{E_{\mathrm{ICE}}}{C p_{\mathrm{ICE}}}\right)+0.6153\right) \eta_{\mathrm{e}, \mathrm{ICE}}^{\text {nom }} \\
\eta_{\mathrm{e}, \mathrm{ICE}}^{\text {nom }}=0.0194 \ln \left(C p_{\mathrm{ICE}}\right)+0.2321 \\
\eta_{t h, \mathrm{ICE}}=\left(0.2656\left(\frac{E_{\mathrm{ICE}}}{C p_{\mathrm{ICE}}}\right)^{3}-0.2972\left(\frac{E_{\mathrm{ICE}}}{C p_{\mathrm{ICE}}}\right)^{2}-0.0939\left(\frac{E_{\mathrm{ICE}}}{C p_{\mathrm{ICE}}}\right)+1.1255\right) \eta_{\mathrm{th}, \mathrm{ICE}}^{\text {nom }}(\mathrm{B} .3)
\end{gathered}
$$




$$
\eta_{t h, \mathrm{ICE}}^{\mathrm{nom}}=\left(0.926-\eta_{e, \mathrm{ICE}}\right) \cdot \eta_{H X}
$$

Maximum and minimum capacities of the ICE which described by Eq. (B.1-B.3) are $3762 \mathrm{~kW}$ and $108 \mathrm{~kW}$, respectively. $\eta_{H X}$ is the heating exchanger efficiency. According to the data in ref. [26], the range of PLR $=E_{\mathrm{ICE}} / C p_{\mathrm{ICE}}$ is 0.4 to 1 . The function in Eq. (B.2) is determined by the statistic analysis of samples in ref. [26], as show in Fig. B.1.

ICE useful life is 20 years [28].The capital cost and maintenance cost coefficient of ICE can be estimated as [29]:

$$
\begin{gathered}
C c_{\text {ICE }}=-280.47 \ln \left(C p_{\text {ICE }}\right)+3711.78 \\
C M_{\text {ICE }}=-0.0031 \ln \left(C p_{\text {ICE }}\right)+0.0394
\end{gathered}
$$

Units of $C c_{\mathrm{ICE}}$ and $C M_{\mathrm{ICE}}$ are $\$ / \mathrm{kW}$ and $\$ / \mathrm{kWh}$, respectively. The coefficient of performance and

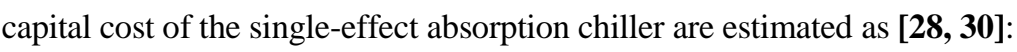

$$
\begin{gathered}
C O P_{a c}=\left\{\begin{array}{cc}
0 & f_{a c}<0.2 \\
-0.6181 f_{a c}^{2}+0.8669 f_{a c}+0.4724 & f_{a c} \geq 0.2
\end{array}\right. \\
C c_{a c}=-36.78 \ln \left(C p_{a c}\right)+369.50
\end{gathered}
$$

where $f_{a c}$ is the part load factor of absorption chiller; $C p_{a c}$ is the capacity of absorption chiller. Unit of $C c_{a c}$ is $\$ / \mathrm{kW}$. The maintenance cost of the absorption chiller is neglected in this study.

The capital recovery factor $R$ is calculated by [4]:

$$
R=\frac{I_{\text {rate }}\left(1+I_{\text {rate }}\right)^{n}}{\left(1+I_{\text {rate }}\right)^{n}-1}
$$

where $I_{\text {rate }}$ is the interest rate; $n$ is the service life of the system. 


\section{References}

[1] Wu DW, Wang RZ. Combined cooling, heating and power: a review. Prog Energ Combust 2006; 32(5): 459-95.

[2] Mago PJ, Chamra LM. Analysis and optimization of CCHP systems based on energy, economical, and environmental considerations. Energ Building 2009; 41(10): 1099-1106.

[3] Wu J, Wang J, Li S. Multi-objective optimal operation strategy study of micro-CCHP system. Energy 2012; 48(1): 472-483.

[4] Wang JJ, Zhang CF, Jing YY. Multi-criteria analysis of combined cooling, heating and power systems in different climate zones in China. Appl Energ, 2010, 87(4): 1247-1259.

[5] Cho H, Smith A D, Mago P. Combined cooling, heating and power: A review of performance improvement and optimization. Appl Energ, 2014, 136: 168-185.

[6] European Summary Report on CHP Support Schemes. A comparison of 27 national support mechanisms. Cogeneration Observatory and dissemination Europe (CODE) project report 2010.

〈 http://www.code-project.eu/wp-content/uploads/2011/02/231210-European-Summary-Rep ort-on-CHP-support-schemes.pdf $>$ Accessed November 27, 2014.

[7] Streckienė G, Martinaitis V, Andersen A N, et al. Feasibility of CHP-plants with thermal stores in the German spot market. Appl Energ, 2009, 86(11): 2308-2316.

[8] Blarke M B. Towards an intermittency-friendly energy system: Comparing electric boilers and heat pumps in distributed cogeneration. Appl Energ, 2012, 91(1): 349-365. 
[9] Combined Heat and Power: A Clean Energy Solution. U.S. Department of Energy (DOE), $\begin{array}{llll}\text { U.S. } & \text { Environmental } & \text { Protection }\end{array}$ $\langle$ http://www.epa.gov/chp/documents/clean_energy_solution.pdf〉 Accessed November 27, 2014.

[10] Energy policies of IEA countries: Japan, 2003 Review. International Energy Agency (IEA) 2003. 〈http://s3.amazonaws.com/zanran_storage/www.iea.org/ContentPages/9954228.pdf〉 Accessed November 27, 2014.

[11] Gu Q, Ren H, Gao W, et al. Integrated assessment of combined cooling heating and power systems under different design and management options for residential buildings in Shanghai. Energ Building 2012; 51: 143-152.

[12] Radulovic D, Skok S, Kirincic V. Cogeneration-investment dilemma. Energy 2012; 48(1): 177-187.

[13] Tichi SG, Ardehali MM, Nazari ME. Examination of energy price policies in Iran for optimal configuration of CHP and CCHP systems based on particle swarm optimization algorithm. Energ Policy 2010; 38(10): 6240-6250.

[14] Sanaye S, Khakpaay N. Simultaneous use of MRM (maximum rectangle method) and optimization methods in determining nominal capacity of gas engines in CCHP (combined cooling, heating and power) systems. Energy 2014; 72: 145-158.

[15] Siler-Evans K, Morgan MG, Azevedo IL. Distributed cogeneration for commercial buildings: Can we make the economics work?. Energ Policy 2012; 42: 580-590. 
[16] Fragaki A, Andersen A N. Conditions for aggregation of CHP plants in the UK electricity market and exploration of plant size. Appl Energ, 2011, 88(11): 3930-3940.

[17] Pade LL, Schröder ST, Münster M, et al. Policy schemes, operational strategies and system integration of residential co-generation fuel cells. Int $\mathbf{J}$ Hydrogen Energ 2013; 38(7): 3050-3063.

[18] Vandewalle J, D'haeseleer W. The impact of small scale cogeneration on the gas demand at distribution level. Energ Convers Manage 2014; 78: 137-150.

[19] Special support mechanism for distributed energy system and gas air conditioner in Shanghai. Shanghai Municipal Gas Management Office $\quad 2013$. $\langle$ http://www.sh-gas.sh.cn/swcms/Open/ShowArticle.asp?ArticleID=773 > Accessed November 27, 2014. (In Chinese)

[20] Zheng C Y, Wu J Y, Zhai X Q. A novel operation strategy for CCHP systems based on minimum distance. Appl Energ 2014; 128: 325-335.

[21] Wang J, Zhai ZJ, Jing Y, et al. Influence analysis of building types and climate zones on energetic, economic and environmental performances of BCHP systems. Appl Energ 2011; 88(9): 3097-3112.

[22] Cao S, Hasan A, Sirén K. Matching analysis for on-site hybrid renewable energy systems of office buildings with extended indices. Appl Energ 2014; 113: 230-247.

[23] Cao S, Hasan A, Sirén K. On-site energy matching indices for buildings with energy conversion, storage and hybrid grid connections. Energ Building 2013; 64: 423-438. 
[24] Cardona E, Piacentino A, Cardona F. Matching economical, energetic and environmental benefits: an analysis for hybrid CHCP-heat pump systems. Energ Convers Manage 2006; 47(20): 3530-3542.

[25] Allison JE, Lents J. Encouraging distributed generation of power that improves air quality: can we have our cake and eat it too? Energ Policy 2002; 30(9): 737-752.

[26] New power systems: Electric power generation (New products, Type: Gas Generator Sets). Caterpillar, 2013. $\langle$ http://www.cat.com/en_US/products/new/power-systems/electric-power-generation.html $\rangle$ Accessed Feb 22, 2016.

[27] TRNSYS 17 transient system simulation TYPE907: Woodward Governor. TRNSYS 17.1 2012.

[28] Firestone, R. Distributed energy resources customer adoption model technology data, Environment Energy Technologies Division. Ernest Orlando Lawrence Berkeley National Laboratory 2004.

[29] Catalogue of CHP Technologies. Compiled by ICF from vendor-supplied data. U.S. $\begin{array}{lllll}\text { Environmental } & \text { Protection } & \text { Agency } & \text { (EPA) }\end{array}$ $\langle$ http://www.epa.gov/chp/documents/catalog_chptech_full.pdf $\rangle$ Accessed November 27, 2014.

[30] Broad, 2013. Selection and design of non-electric air conditioning. Broad 2013. $\langle$ http://www.broad.com/uploads/pdf/xxfiktxxsjsc.pdf〉 Accessed November 27, 2014. (In Chinese) 
[31] Shanghai Municipal Development \& Reform Commission (SMDRC), 2011. Adjustment notification of electricity price in Shanghai. Shanghai Municipal Development \& Reform

Commission

(SMDRC)

2011.

< http://www.shdrc.gov.cn/main?main_colid=319\&top_id=312\&main_artid=19986

Accessed November 27, 2014. (In Chinese)

[32] Wu Q, Ren H, Gao W, et al. Multi-criteria assessment of combined cooling, heating and power systems located in different regions in Japan. Appl Therm Eng, 2014, 73(1): 660-670.

[33] Karami R, Sayyaadi H. Optimal sizing of Stirling-CCHP systems for residential buildings at diverse climatic conditions. Appl Therm Eng, 2015, 89: 377-393.

[34] Wang JJ, Jing YY, Zhang CF, et al. Review on multi-criteria decision analysis aid in sustainable energy decision-making. Renew Sust Energ Rev, 2009, 13(9): 2263-2278.

[35] Farahnak M, Farzaneh-Gord M, Deymi-Dashtebayaz M, et al. Optimal sizing of power generation unit capacity in ICE-driven CCHP systems for various residential building sizes. Appl Energ, 2015, 158: 203-219.

[36] Tian Z, Niu J, Lu Y, et al. The improvement of a simulation model for a distributed CCHP system and its influence on optimal operation cost and strategy. Appl Energ, 2016, 165: 430-444.

[37] Li L, Mu H, Gao W, et al. Optimization and analysis of CCHP system based on energy loads coupling of residential and office buildings. Appl Energ, 2014, 136: 206-216. 
[38] Balyani H H, Sohani A, Sayyaadi H, et al. Acquiring the best cooling strategy based on thermal comfort and $3 \mathrm{E}$ analyses for small scale residential buildings at diverse climatic conditions. Int J Refrig, 2015, 57: 112-137. 
Table 1 Main parameters employed for evaluation and analysis.

\begin{tabular}{|c|c|c|c|}
\hline Variable & Symbol & Unit & Value \\
\hline COP of electric chiller [20] & $C O P_{e c}$ & - & 4.0 \\
\hline Heating exchanger efficiency [22] & $\eta_{H X}$ & $\%$ & 80.0 \\
\hline Boiler efficiency [22] & $\eta_{b}$ & $\%$ & 85.0 \\
\hline Low heat value of natural gas & $L H V$ & $\mathrm{kWh} / \mathrm{m}^{3}$ & 9.86 \\
\hline Favorable price of natural gas ${ }^{a}$ & $p_{f 1}$ & $\$ / \mathrm{m}^{3}$ & 0.479 \\
\hline Normal price of natural gas ${ }^{a}$ & $p_{f 2}$ & $\$ / \mathrm{m}^{3}$ & 0.712 \\
\hline Price of electricity ${ }^{a}$ & $p_{e, \text { in }}$ & $\$ / \mathrm{kWh}$ & 0.160 \\
\hline Project lifetime [15] & Pro $_{\text {life }}$ & $\mathrm{yr}$ & 15 \\
\hline Interest rate & $I_{\text {rate }}$ & $\%$ & 7 \\
\hline
\end{tabular}

${ }^{a}$ These parameters are the energy price based on the policy of Shanghai $[\mathbf{1 9}, \mathbf{3 1}]$.

Table 2 Unit price of the facilities in the CCHP system [21].

\begin{tabular}{lccc}
\hline Facility & Heating exchanger & Boiler & Electric chiller \\
\hline Unit price, $\$ / \mathrm{kW}$ & 31.02 & 46.53 & 150.45 \\
\hline
\end{tabular}

Table 3 The characteristic of energy production for four operation strategies.

\begin{tabular}{|c|c|}
\hline $\begin{array}{l}\text { Operation } \\
\text { strategy }\end{array}$ & The characteristic of energy production \\
\hline $\mathrm{OS}_{1}$ & $\begin{array}{l}\text { The least excess heat and electricity would be produced. The amount of energy from } \\
\text { CCHP system used to satisfy the demand would be limited. }\end{array}$ \\
\hline $\mathrm{OS}_{2}$ & $\begin{array}{l}\text { The electricity demand is satisfied preferentially. The least excess electricity would } \\
\text { be produced while some of heat is wasted. }\end{array}$ \\
\hline $\mathrm{OS}_{3}$ & $\begin{array}{l}\text { The thermal demand of building will be fulfilled first. The least waste heat would be } \\
\text { produced while some of excess electricity is produced. }\end{array}$ \\
\hline $\mathrm{OS}_{4}$ & $\begin{array}{l}\text { The larger demand between thermal demand and electrical demand is satisfied } \\
\text { preferentially. The largest excess heat and electricity would be produced. }\end{array}$ \\
\hline
\end{tabular}




\section{Figure captions:}

Fig.1 Cooling, heating and power demands of the hospital in different climate zones.

Fig.2 Energy flows of CCHP system.

Fig.3 CCHP system operation strategies analyzed in this paper.

Fig.4 Optimization method of CCHP system to solve ATCSR or PER optimization.

Fig.5 The ATCSR, PER, OEF, and OEM of CCHP system for different operation strategies under $\mathrm{Pol}_{1}$ and under $\mathrm{Pol}_{2} \& \mathrm{Pol}_{3}$ with $p_{e, \text { out }}^{\text {ben }}=0 \quad ¥ / \mathrm{kWh}\left(C_{P_{I C E}}=1000 \mathrm{~kW}\right.$ and Min-PLR=0.4).

Fig.6 The comparison of the performance of CCHP system between ATCSR optimization and PER optimization when ICE capacity is equal to $1275 \mathrm{~kW}$ under $\mathrm{Pol}_{2}$.

Fig.7 The impact of selling price on PER as function of PER ${ }^{\text {ben }}$ when optimizing ATCSR under $\mathrm{Pol}_{3} .\left(C p_{I C E}=1275 \mathrm{~kW}\right.$ and $\left.K=0\right)$

Fig.8 The comparison of the ATCSR and PER between $\mathrm{Pol}_{2}$ and $\mathrm{Pol}_{3}$ when optimizing ATCSR. $\left(C p_{I C E}=1275 \mathrm{~kW}\right.$ and $\left.\mathrm{PER}^{\text {ben }}=70 \%\right)$

Fig.9 The impact of $K$ on ATCSR as a function of ICE capacity when optimizing ATCSR under $\mathrm{Pol}_{3} .\left(p_{e, \text { out }}^{\text {ben }}=0.875 \quad ¥ / \mathrm{kWh}\right.$ and $\left.\mathrm{PER}^{\text {ben }}=70 \%\right)$

Fig.10 The ATCSR, PER, selection of prime mover capacity, selection of operation strategies, and the ratio $E_{\text {grid,out }}$ to total electricity demand of CCHP system in different climate zones under different feed-in tariff policies. $\left(\mathrm{Pol}_{2}: p_{e, \text { out }}^{\text {ben }} / p_{e, \text { in }}=0.848\right.$; 
$\left.\mathrm{Pol}_{3}{ }^{a}: p_{e, \text { out }}^{\text {ben }} / p_{e, \text { in }}=0.848, \mathrm{PER}^{\text {ben }}=70 \%, K=0 ; \mathrm{Pol}_{3}{ }^{b}: \quad p_{e, \text { out }}^{\text {ben }} / p_{e, \text { in }}=0.848, \mathrm{PER}^{\text {ben }}=70 \%, K=5\right)$

Fig.11 The comprehensive assessment of feed-in tariff policy in different climate zones.

Fig. B1 Fitting function between nominal power generation efficiency and ICE capacity of samples in ref. [32]. 


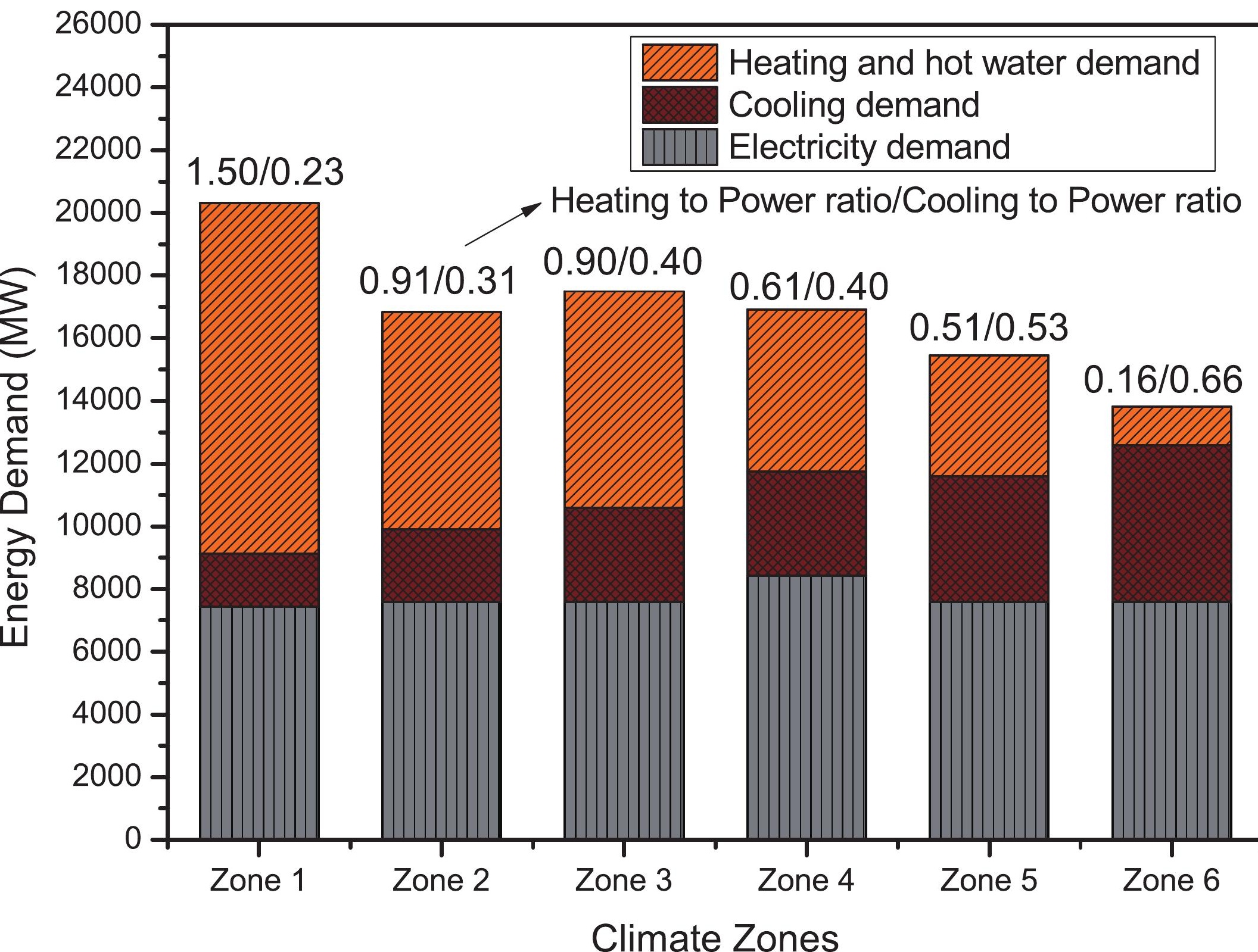




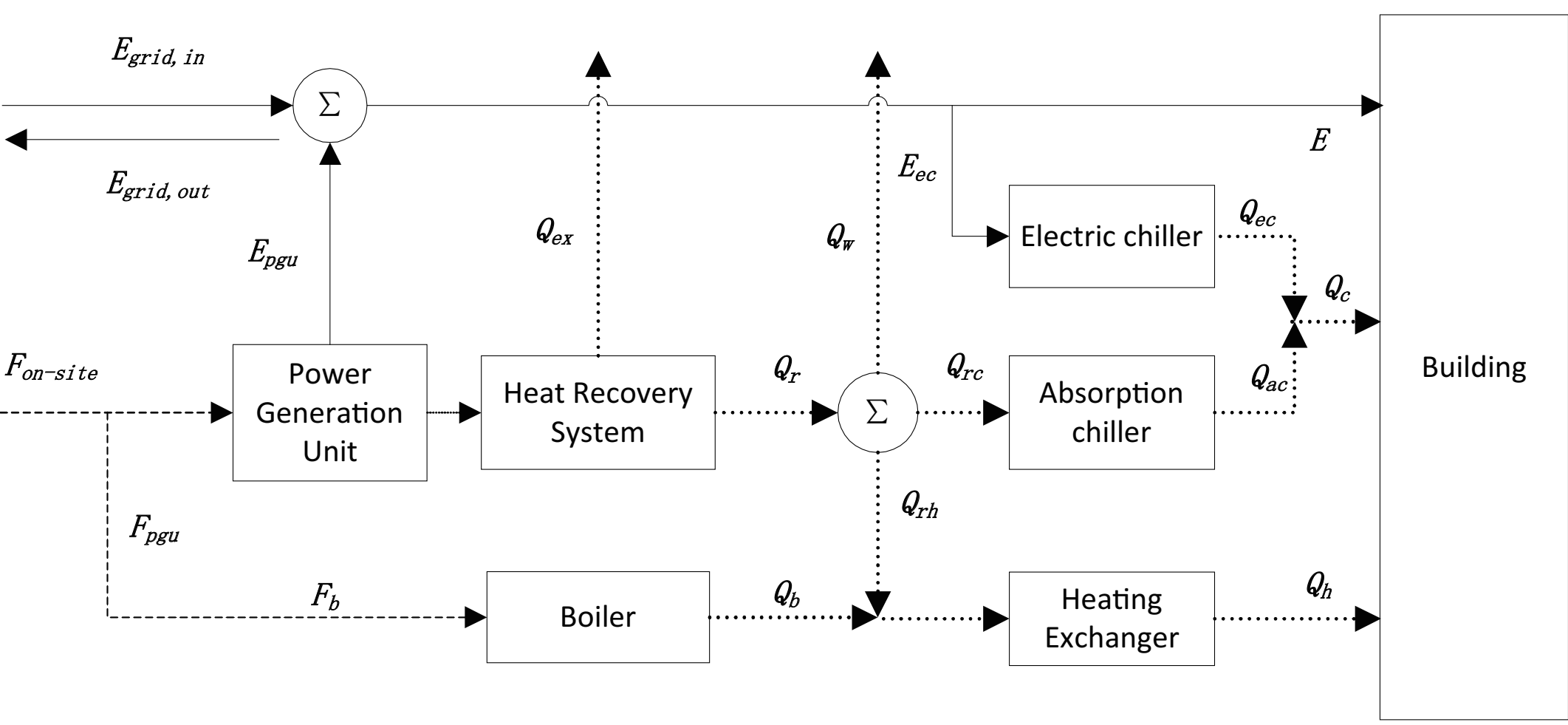


Objective function: $\max \{\mathrm{ATSCR}\}$ or $\max \{\mathrm{PER}\}$

Decision variable: Prime mover capacity $C p_{p g u} \&$ value of Min-PLR Approach: Compare ATCSR or PER of different operation strategies

Different operation strategies: $O S_{1}, \mathrm{OS}_{2}, \cdots, O S_{n}$

Approach: Optimize the objective function by decision variables

Decision variable: $C p_{p g u}$

Constraint: Facility constraints

Approach: Golden section algorithm based on the optimal result achieved by optimizing Min-PLR

Decision variable: $M i n-P L R$

Constraint: Energy balance constraints

Approach: Golden section algorithm 


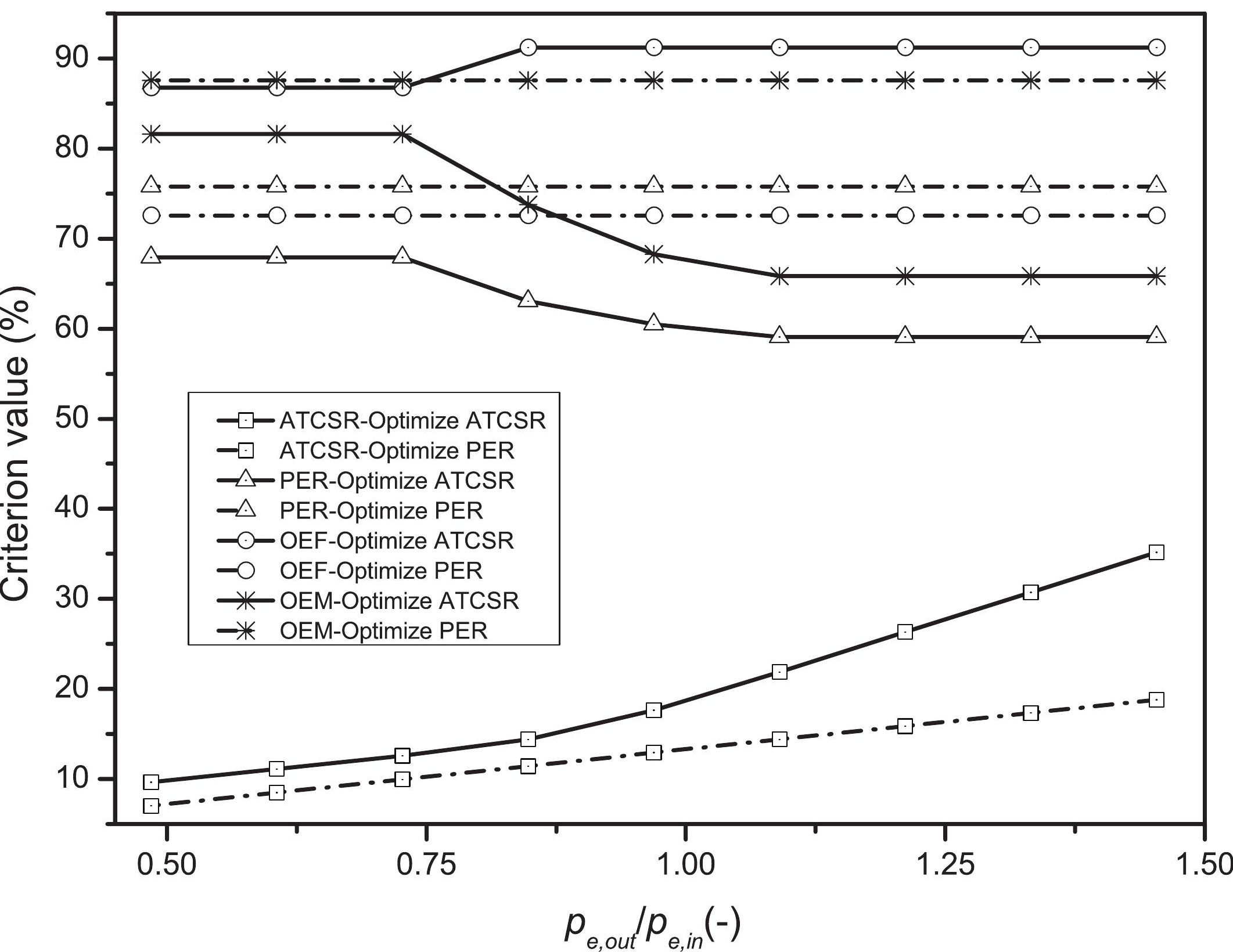




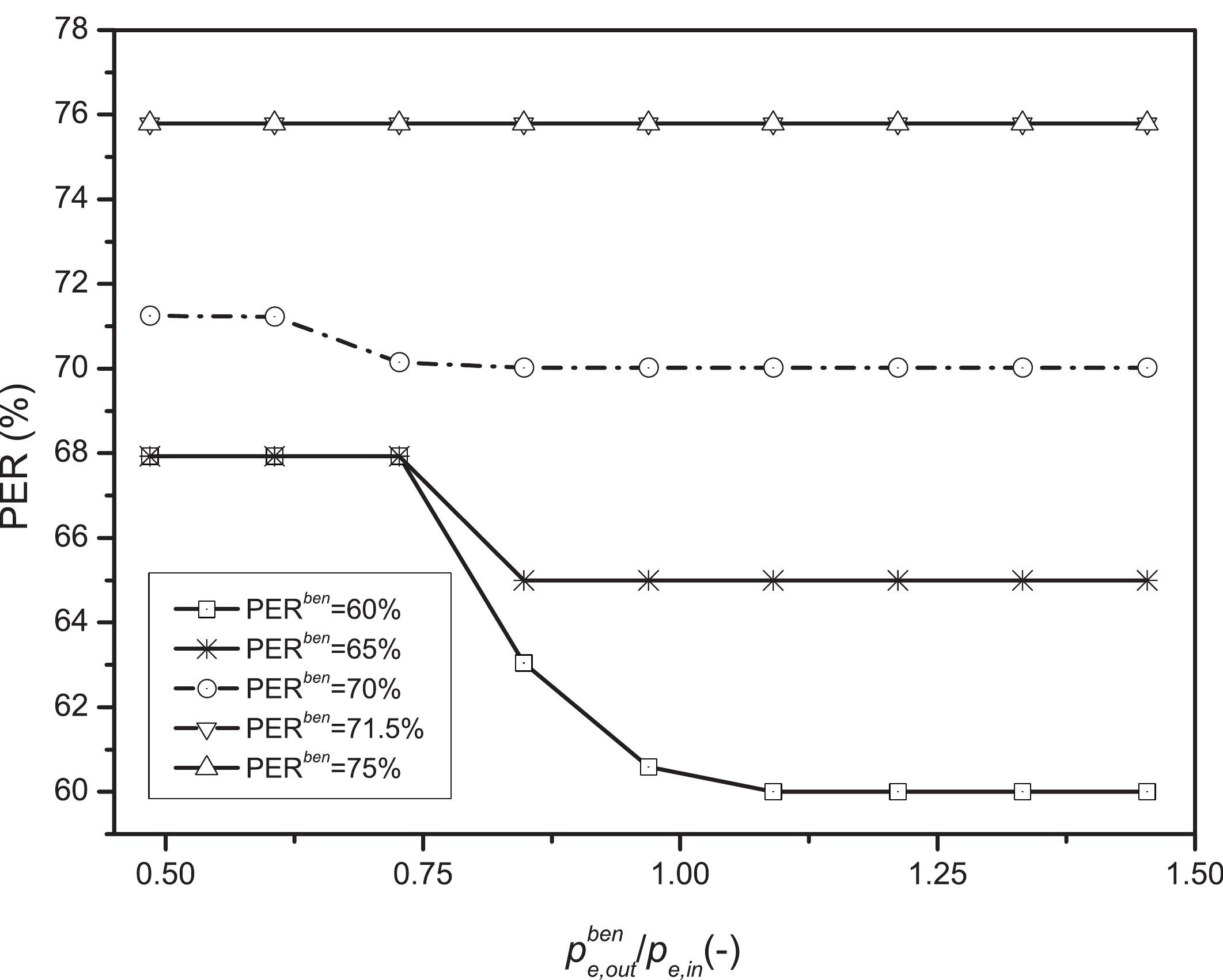




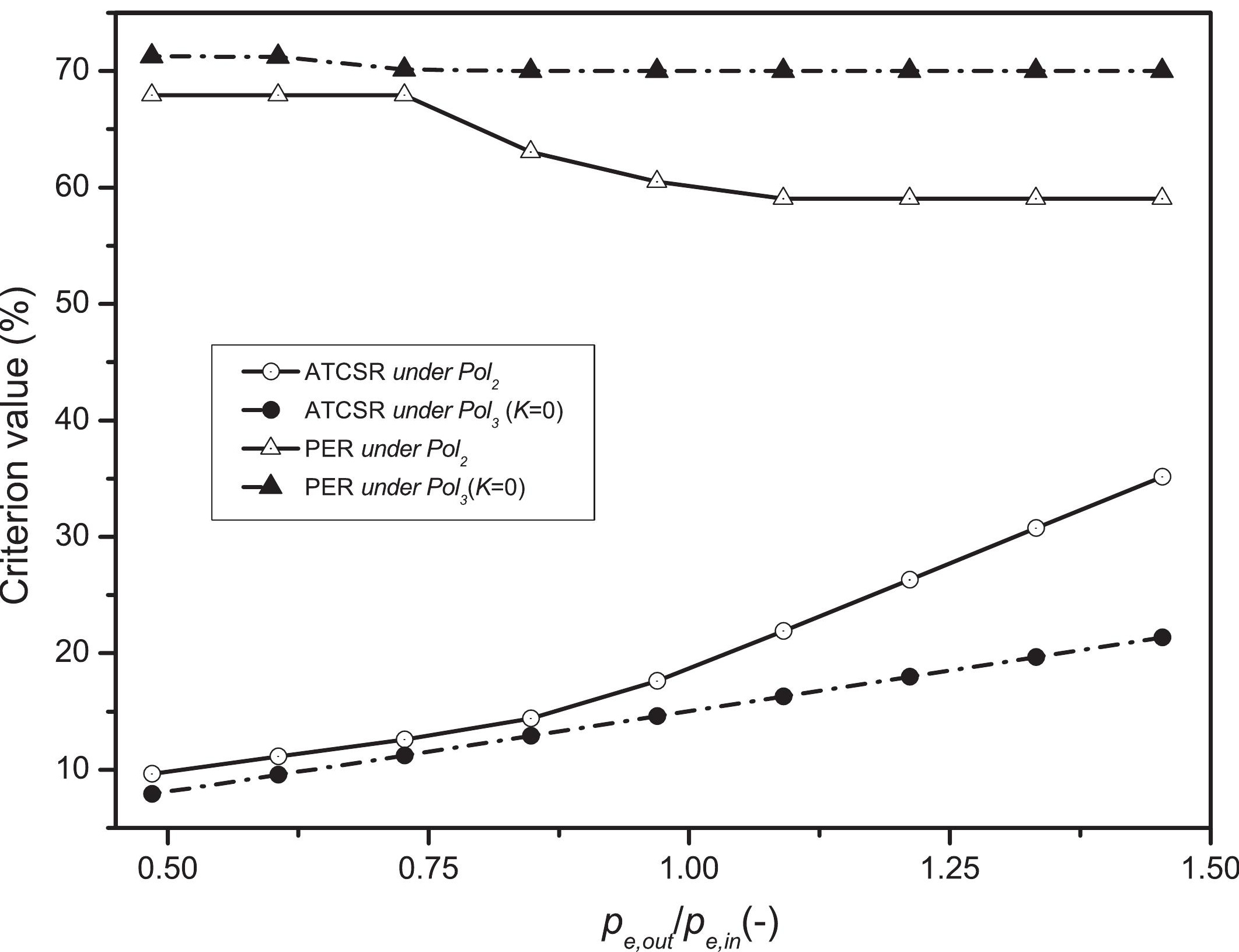




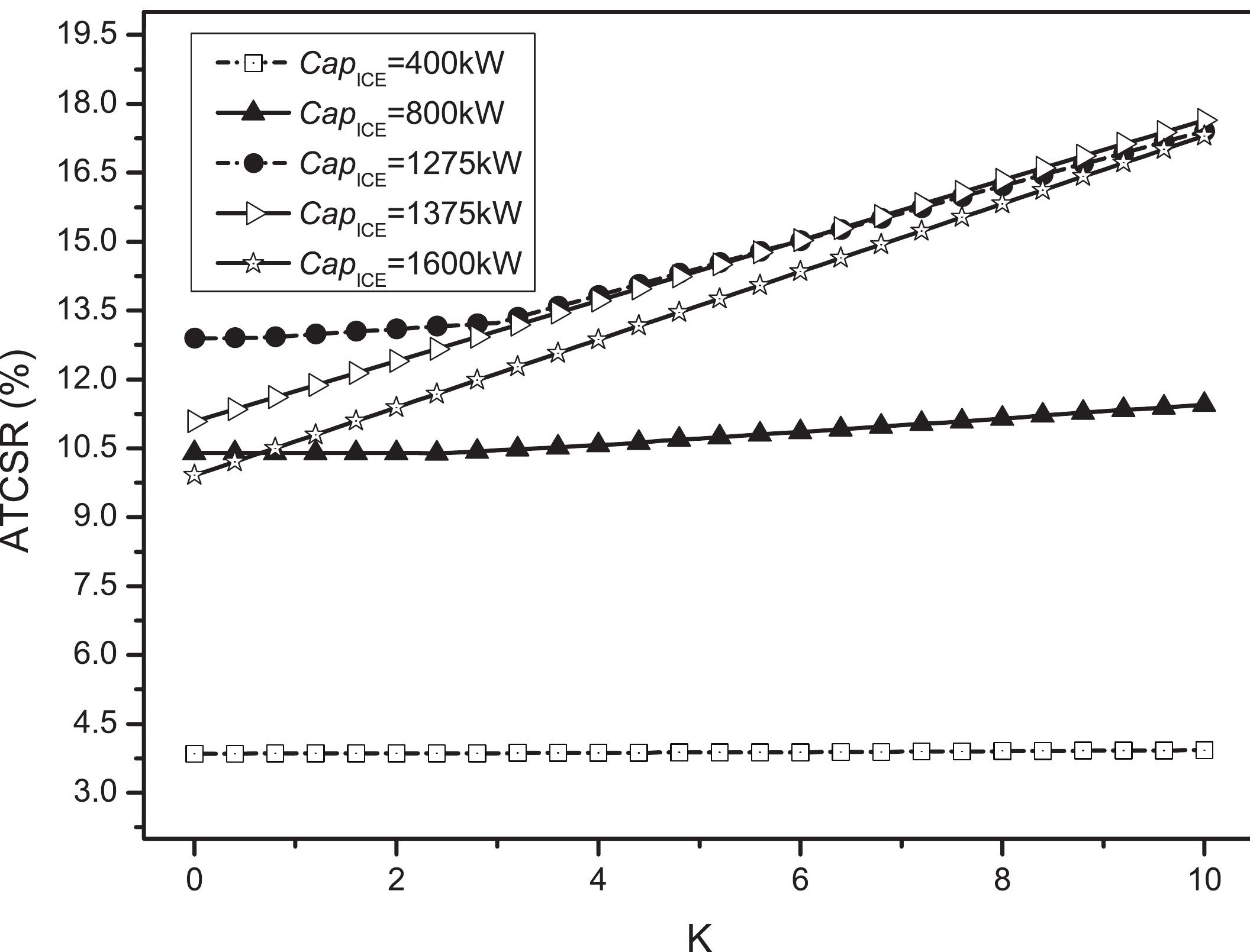



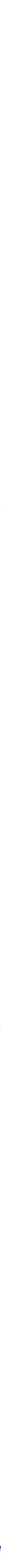


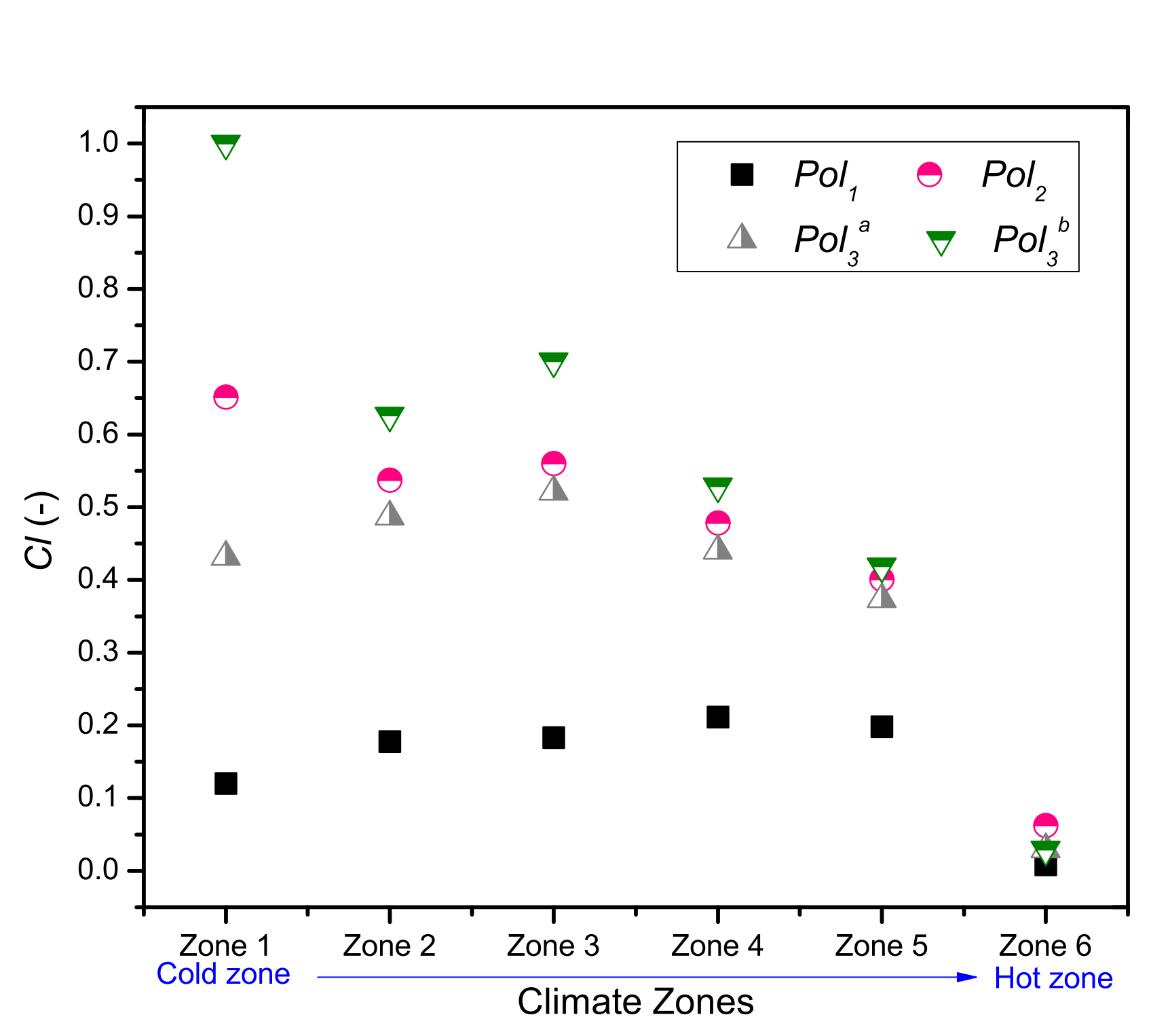

Figure11

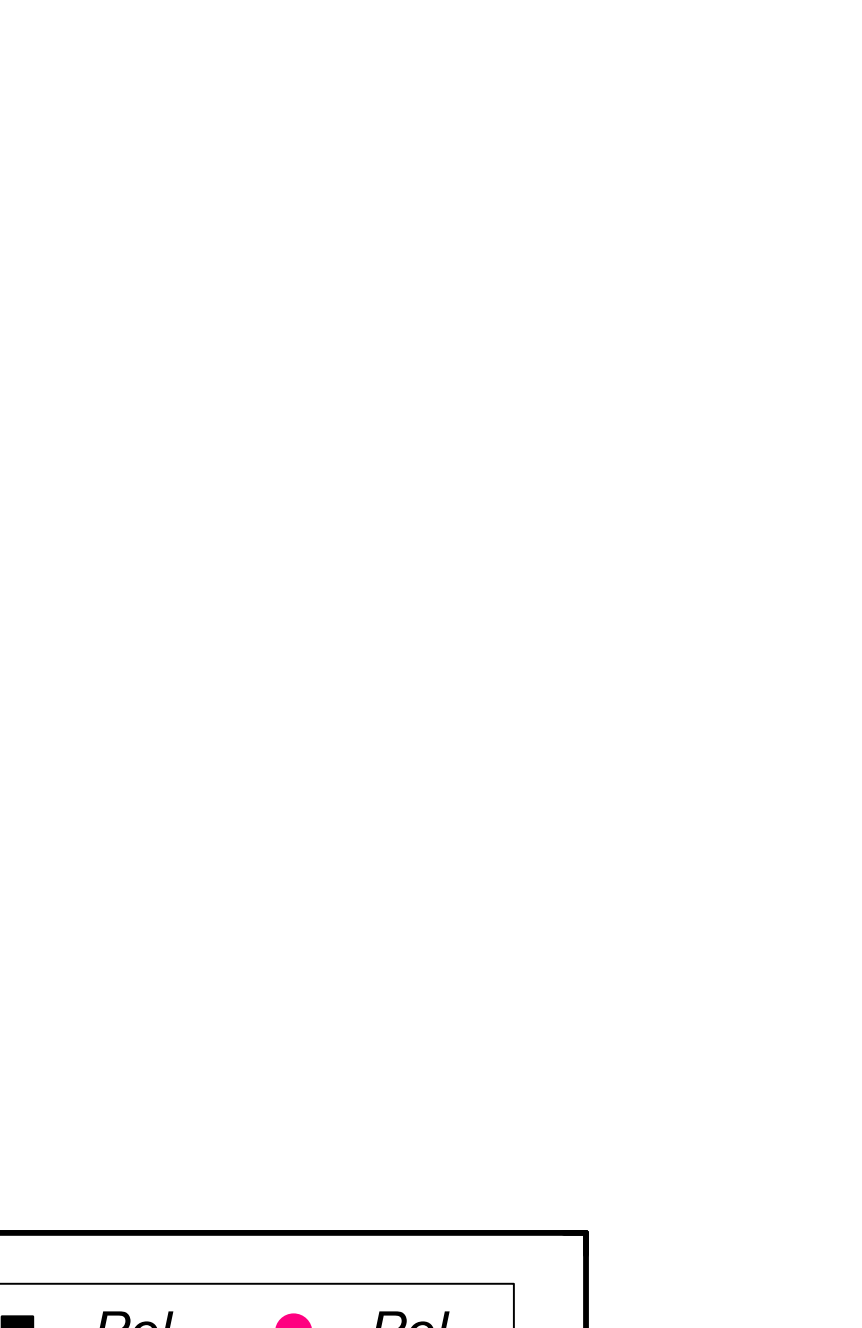




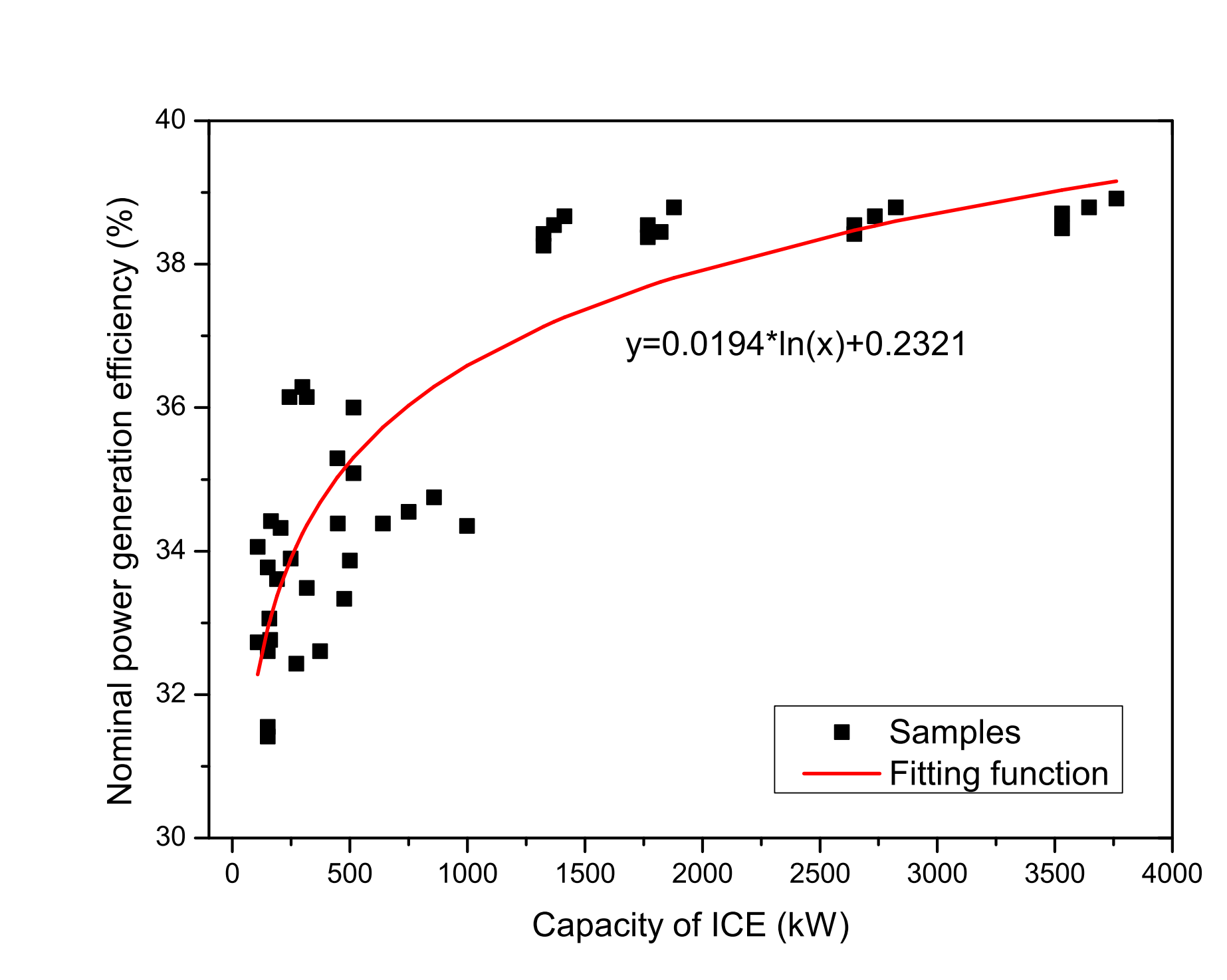

FigureB1

.

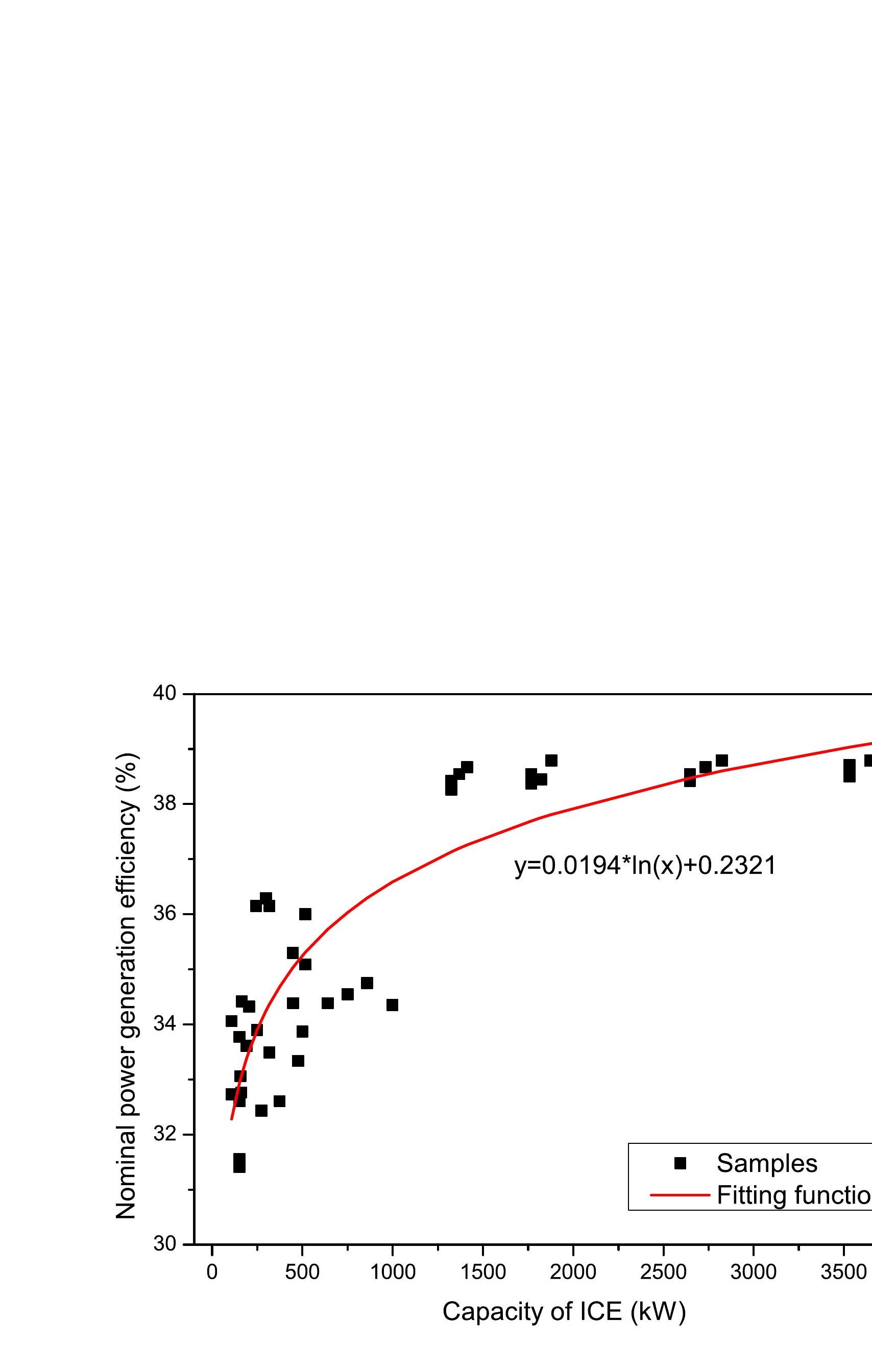

